\title{
Climatic modeling of the distribution of Oxytropis triphylla (Fabaceae) by maximum entropy method
}

\author{
Konstantin Baikov ${ }^{1, *}$, and Denis Krivenko ${ }^{2}$ \\ ${ }^{1}$ Central Siberian Botanical Garden SB RAS, Novosibirsk, Russia \\ ${ }^{2}$ Siberian Institute of Plant Physiology and Biochemistry SB RAS, Irkutsk, Russia
}

\begin{abstract}
Predictive spatial models of the distribution of Oxytropis triphylla (Pall.) Pers. (Fabaceae), an endemic species of Baikal Siberia, were generated in MAXENT computer program using maximum entropy method. Long-term data of air temperatures for every month of the year were downloaded from the world database of open access WorldClim. Modeling was performed separately for minimum, average and maximum temperatures. Each variable contribution to the modeling was the basis to select the key variables having higher influence on the obtained models. The selected 10 key variables are the following: minimum temperatures of December and January; average temperatures of October, December, January and February; maximum temperatures of November, December, January and February. Then a model of the second level was calculated using only the ten key variables. There are three northern localities in the zone of adverse temperature effects: cape Malyi Cheremshanyi, Chencha and Sakhuli villages (all of them are in the Republic of Buryatia). It has been experimentally confirmed that the values of the key variables along the coasts of the Maloe More of Lake Baikal (Irkutskaya Oblast) are the most favorable for habitation of $O$. triphylla in this part of its range.
\end{abstract}

\section{Introduction}

The results of modeling the distribution of plants and animals according to climatic and bioclimatic variables by the maximum entropy method have been published in many foreign journals as well as in Russian scientific publications in the last few years [1-3]. Interest to the implementation of such studies is due to the high information content of the predictive models obtained. In this study, the maximum entropy method was used to conduct a quantitative analysis of the climatic temperature factors that limit the range of Oxytropis triphylla (Pall.) Pers., the endemic species of Baikal Siberia [4, 5].

\section{Materials and Methods}

\footnotetext{
${ }^{*}$ Corresponding author: kbaikov2018@mail.ru
} 
Specimens of $O$. triphylla, stored in the herbarium collections of Central Siberian Botanical Garden of SB RAS (Novosibirsk, Russia), Siberian Institute of Plant Physiology and Biochemistry of SB RAS (Irkutsk, Russia) and V.L. Komarov Botanical Instutute of RAS (Saint-Petersbourg, Russia) were taken as the materials for the study. For the construction of the predictive models, 45 localities were chosen. Accurate geolocation references were determined for these localities. The predictive spatial models were generated in the MAXENT computer program by the maximum entropy method [6-9]. Values of climatic indicators were downloaded from the world database of open access WorldClim http://worldclim.org/.

\section{Results and Discussion}

Initially, climate models were constructed separately for minimum, average and maximum temperatures of each month of the year. The variables contribution to the modeling was the basis to select the set of the key variables having higher influence on the models obtained. The selected ten key variables are the folowing: minimum temperatures of December and January; average temperatures of October, December, January and February; maximum temperatures of November, December, January and February. Then a model of the second level was calculated using only the ten key variables (Fig. 1).

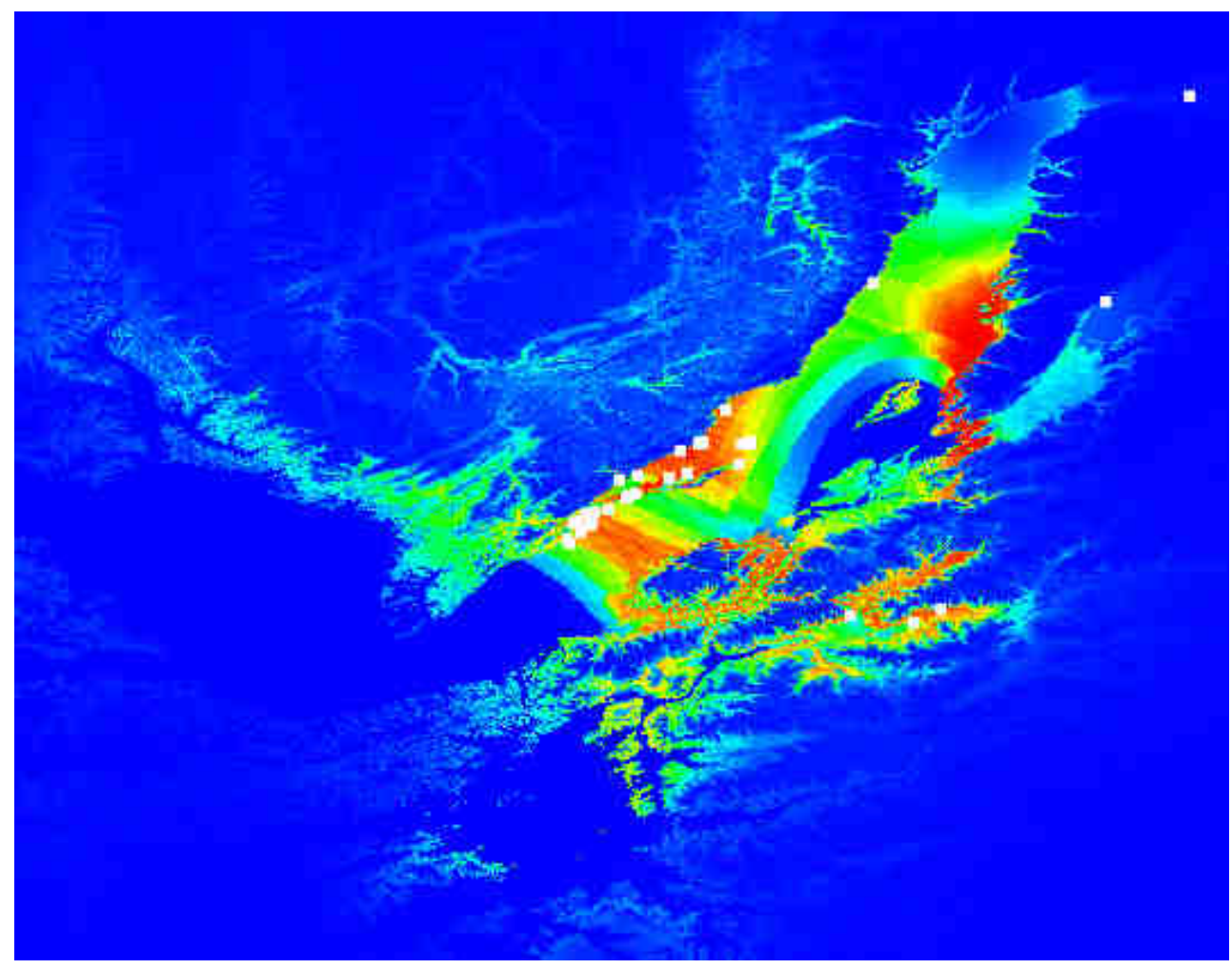

Fig. 1. The predictive spatial model of Oxytropis triphylla range constructed on 10 key temperature indicators. Explanations are given in the text.

In Fig. 1, the areas with the temperature regimes which determine the probability of finding O. triphylla within the interval of $0.93-1.00$, or $93-100 \%$ are coloured in red; with probability $0.86-0.92$ are coloured dark orange; with probability $0.78-0.85$ - orange; and $0.70-0.77$ - yellow. Thus, red-orange-yellow gamma indicates the favorable parts of Baikal 
Siberia where this species may be found. Different tones of the colour blue indicate areas that are unfavorable for habitats of the species: in the dark blue areas the probability of finding varies in the range $0.00-0.08$; in the pure blue areas $-0.09-0.15$; in the light blue $0.16-0.23$; in the very light blue $-0.24-0.31$.

Different tones of the green colour indicate areas with the probability of finding the species from 0.32 to 0.69 . Green coloured areas may be considered as neutral and even close to favorable for the species. White squares correspond to geographical points where the herbarium specimens were collected and included in the modeling (45 localities). Some of them are located very closely to each to other; thus, they look as the same white square.

According to the obtained predictive spatial model, the main fragment of the range of $O$. triphylla is located in the middle part of the Western coast of Lake Baikal (38 localities). Therefore, it can be considered experimentally confirmed that values of the key temperature variables near the coasts of the Maloe More of the Lake Baikal (Irkutskaya Oblast) are the most favorable for habitation of $O$. triphylla in this fragment of its range. Accordingly, new populations of this endemic species may be found in this territory.

Another range fragment includes only three localities in Southern Buryatiya. These localities are placed a long distance from the main part of the range described above (150$200 \mathrm{~km}$ ). Regimes of key temperature indicators in Southern Buryatiya allow predicting a high probability to find $O$. triphylla in a new neighbouring locations.

Three northern localities (cape Malyi Cheremshanyi on the Western Coast of Lake Baikal, Chencha and Sakhuli villages - all in the Republic of Buryatia) are disposed far from the main part of the range. According to the predictive spatial model in Fig. 1, these populations inhabit the zone of adverse temperature effects, especially in the neighborhood of Chencha and Sakhuli villages.

The contribution of variables to the construction of the predictive spatial model for $O$. triphylla is presented on the column diagram in Fig. 2, where the dark blue colour columns show the value of the variable when it is taken into account independently of the others; the light-blue colour columns show the result of excluding the variable from the prediction across the entire set of variables; the lower (red) column demonstrates the total contribution of all the variables to the constructed model.

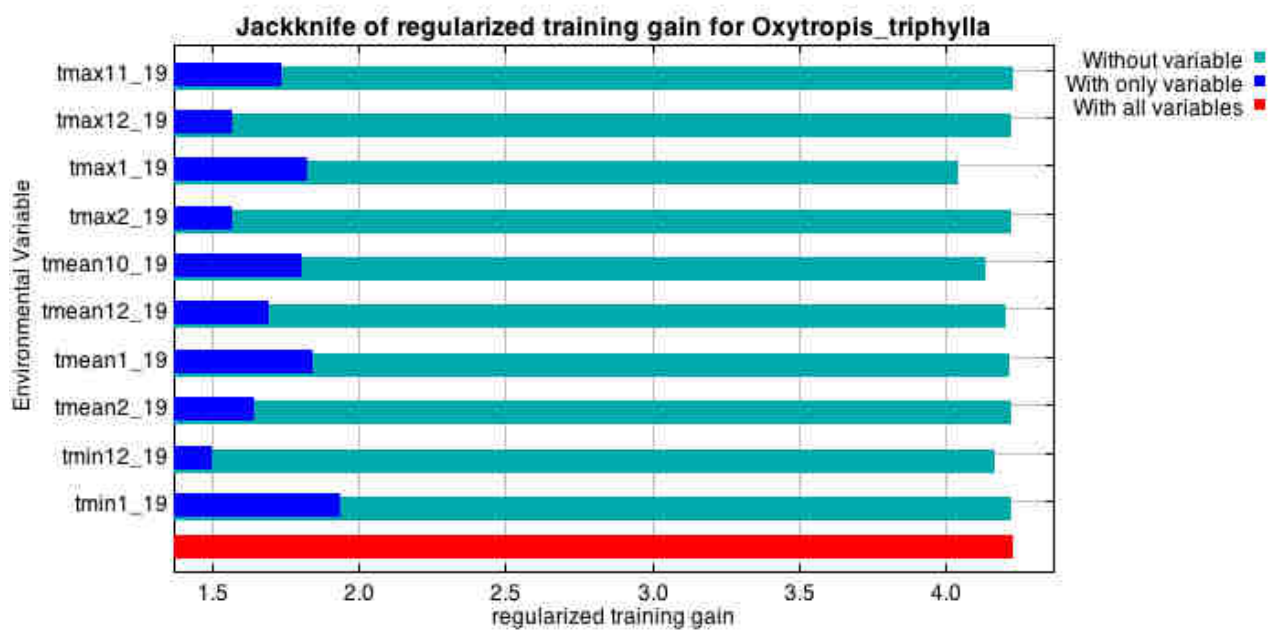

Fig. 2. The diagram of contribution of key temperature indicators to the spatial predictive model of Oxytropis triphylla.

According to the individual contribution, the three leading variables are the following (in descending order of values): the minimum temperature in January (tmin1_19), the 
average temperature in January (tmean1_19) and the maximum temperature in January (tmax1_19).

Consequently, favorable temperature regimes in January largely determine the parts of the range with a high probability of $O$. triphylla finding. The average temperature in October (tmean10_19) and the maximum temperature in November (tmax11_19) also have high significance. The elimination of any variable from the full set of indicators leads to decreasing the training role of the full set, the most noticeable after excluding the maximum temperature of January (tmax1_19), the minimum temperature of December (tmin12_19) and the average temperature of October (tmean10_19).

The work was carried out within the framework of the state task of the Central Siberian Botanical Garden of SB RAS for the project AAAA-A17-117012610055-3 "Biological diversity of cryptogamous organisms (algae, fungi, lichens) and vascular plants in the geospace of biotic and abiotic factors, assessment of their role in water and terrestrial ecosystems of Northern Asia" with the partial support of the Russian Foundation for Basic Research (project No. 16-04-01399A). In preparing the publication, the materials of the bioresource scientific collection of CSBG SB RAS "Herbarium of Higher Vascular Plants, Lichens and Fungi (NS, NSK)" UNU No. USU 440537 were used. The research was done using the collection of the Core Facilities Center "Bioresource Center" at the Siberian Institute of Plant Physiology and Biochemistry SB RAS (Irkutsk, Russia).

\section{References}

1. D.V. Sandanov, Uchenye zapiski Zabaikalskogo Gosudarstvennogo Universiteta 11, 38-45 (2016)

2. D.V. Sandanov, B.B. Naidanov, Rastitelnyi Mir Aziatskoi Rossii 3, 30-35 (2015)

3. S. V. Solodyankina, E. A. Istomina, A. A. Sorokovoi, V. V. Chepinoga, Geography and Natural Resources 5, 92-99 (2016)

4. L. I. Malyshev, Genus Oxytropis (Conspect of the flora of Asian Russia: Vascular plants, Novosibirsk, 2012)

5. D.G. Chimitov, O.V. Imetkhenova, B.B. Naidanov, Rastitelnyi Mir Aziatskoi Rossii 1, 10-18 (2017)

6. S.J. Phillips, R.P. Anderson, R.E. Schapire, Ecol. Modeling 190, 231-259 (2006)

7. S.J. Phillips, M. Dudik, Ecography 31, 161-175 (2008)

8. S.J. Phillips, M. Dudik, R.E. Schapire, Proceedings of the $21^{\text {st }}$ Intern. Conf. on Machine Learning (ACM, New York, 2004)

9. J. Elith, S. J. Phillips, T. Hastie, et al., Diversity Distrib 17, 43-57 (2011) 